\title{
Adherence in HIV-I infected children taking once daily HAART with Didanosine + Lamivudine + Efavirenz in West Africa. ANRS I 2 | 03 clinical trial
}

Jerôme Somé*1, Boubacar Nacro1, Hervé Hien², Hassane Tamboura1, Emmanuelle Zouré ${ }^{1}$, Serge Diagbouga ${ }^{2}$, Adama Ouiminga ${ }^{2}$, Aly Drabo², Alain Hien ${ }^{1}$, Souleymane Yaméogo ${ }^{1}$, Philippe Van de Perre ${ }^{3}$ and Philippe Msellati ${ }^{4}$

Address: ${ }^{1}$ Service de Pédiatrie, CHU Sourô Sanou, Bobo-Dioulasso, Burkina Faso, ${ }^{2}$ Centre Muraz, Bobo-Dioulasso, Burkina Faso, ${ }^{3}$ Laboratoire de bactériologie-Virologie, CHU de Montpellier, Hôpital Arnaud de Villeneuve,, Montpellier, France and ${ }^{4}$ UMR 145, IRD, Centre de Recherche Cultures Santé Sociétés/IFEHA, Université Paul Cézanne, Aix en Provence, France

* Corresponding author

from Fifth Dominique Dormont International Conference. Mother-to-child transmitted viral diseases: from transmission to children care Paris, France. 26-28 March 2009

Published: 22 July 2009

Retrovirology 2009, 6(SuppI I):PI7 doi:I0.1 186/1742-4690-6-SI-PI7

This abstract is available from: http://www.retrovirology.com/content/6/SI/PI7

(c) 2009 Somé et al; licensee BioMed Central Ltd.

\section{Objective}

Assess adherence and determine the reasons of poor adherence in HIV-1 infected children taking once-a-day paediatric HAART with DDI+3TC+EFV in Bobo-Dioulasso, Burkina Faso.

\section{Methods}

Fifty-two HIV-1 infected children were followed during a 12-month period of the II phase clinical trial. Adherence was assessed using monthly pill counts. A questionnaire was administered quarterly in order to investigate reasons of poor adherence.

\section{Results}

During the 12 months of follow up, two children died. Seven became resistant and 118 questionnaires were administered. Only two caregivers declared missed takings the previous week, which was contrasting with the counting. The difficulties reported by the caregivers were related to the time slot, and the instruction to take the pills on an empty stomach, the length of the treatment, the ARV's form and palatability.
The adherence rate was $98 \%$ and $32 \%$ of the patients had always had an adherence rate $\geq 95 \%$. The adherence was not correlated to the socio-demographic factors and to the immuno-virological response.

\section{Conclusion}

Good adherence of this once daily's treatment study. No association between adherence, the socio-demographic factors and the infection's markers. 